\title{
Correlation of peak expiratory flow rate with body mass index in school children of a government school of Kathmandu
}

\section{Nepal A}

Archana Nepal, Lecturer; Department of Pediatrics, Patan Academy of Health Sciences, Lalitpur, Nepal.

\begin{abstract}
Background: Peak expiratory flow rate is a reliable data to assess the severity and effectiveness of management in adolescent with asthma. There is no study done in Nepalese children to relate it with the body mass index. The present study tries to find out its relation with age, sex, weight, height, body mass index.

Objectives: To identify the effect of body mass index on peak expiratory flow rate among healthyNepalese school children.

Methodology: Three hundred and ten students of a government school at Kalimati wereincluded in this study. Highest of the three peak expiratory flow rate readings were recorded using Wright's peak flow meter. Questionnaire were used to find out the pre-existing disease conditions for exclusion from the study population. Weight and height were measured using standardized instruments and body mass index was calculated using formula: weight $(\mathrm{kg}) / \mathrm{height} \mathrm{t}^{2}(\mathrm{~m})$.

Results: Peak expiratory flow rate initially increased with increasing body mass index from -1SD to +2SD and it declined as body mass index increased above +2 SD. Pearson's correlation $r$ was positive with values of $0.7,0.65,0.64,0.35$ for height, weight, age and body mass index respectively. Height had highest positive correlation with peak expiratory flow rate while body mass index though had positive but weak correlation with peak expiratory flow rate.

Conclusion: Body mass index is positively correlated with peak expiratory flow rate. However, mean Peak expiratory flow rate initially increases with increasing body mass index and it starts declining as body mass index reaches overweight range.
\end{abstract}

Key words: Body mass index; Peak expiratory flow rate; School children

DOI: https://doi.org/10.3126/jkmc.v8i1.25267

\section{INTRODUCTION}

$\mathrm{P}$ eak expiratory flow rate (PEFR) gives the measure of maximal expiratory flow rate sustained by a subject for at least 10 milliseconds expressed in Liter per minute. It is used for assessment and management of asthma control as it measures the level of airway obstruction ${ }^{1,2}$. PEFR varies in an individual according to the age, sex and anthropometric variables ${ }^{3}$. According to Seo. WH et al, PEFR increases with increasing height showing a positive correlation with R2 of 0.81 in boys and 0.76 in girls. The same study has also shown that PEFR is positively correlated with body surface area, weight and age $^{3}$.

Address for correspondence

\section{Dr. Archana Nepa}

Lecturer, Department of Pediatrics

Patan Academy of Health Sciences, Lalitpur, Nepal

E-mail: archuuana@gmail.com
Increasing body mass index (BMI) above the normal range for age puts children at increased risk of respiratory symptoms, such as breathlessness, particularly during exercise, even if they have no obvious respiratory illness ${ }^{4}$. On contrary, malnutrition (BMI below the normal range for age) is also associated with impairment of PEFR perhaps because of slow growth of the larger airways ${ }^{5}$.

\section{METHODOLOGY}

This is an observational study done on school children of Nil Barahi Higher Secondary School, Kalimati, Kathmandu, Nepal. All the students aged seven to sixteen years studying in grade three to nine who fulfilled the inclusion criteria were included in the study. Those children having pre-existing cardiac diseases (congenital heart disease, Rheumatic heart disease), respiratory diseases (asthma; tuberculosis), who had suffered from cough and cold in recent two weeks period and who had chest pain or having chest deformity were excluded from the study. 
Written consent was taken from the Principal of the school and students were given a consent form to be signed by their guardian a day ahead after explaining the research purpose and method. Only those children who were given consent by their guardian were included in the study. Those children who had one or more of the exclusion criteria were excluded from the study later. Digital weighing scale from Secca company was used for taking weight after standardization, and height was measured using stadiometer provided by UNICEF. BMI was calculated using formula weight (kg) / height $\left(\mathrm{m}^{2}\right)$. PEFR was measured using wright's peak flow meter. PEFR was measured in standing position, three measurements were taken and the highest reading of the three was recorded.

SPSS was used for analysis of the data. Correlation study was done using bivariate Correlation. Pearson's correlation $r$ and $P$ values were calculated for correlation of anthropometric variables and BMI with PEFR.

\section{RESULTS}

Out of the 310 students, 10 were excluded from the study due to presence of one or more of the exclusion criteria. Demographic details of the students are in table 1. Change in mean peak expiratory flow rate at different age for male and female is displayed in figure 1 and change in mean peak expiratory flow rate with height is shown in figure 2 .

The mean PEFR increases as BMI increases to normal range and it declines as the $\mathrm{BMI}$ increases overweight range (Table 2 ).

Height, weight, BMI and age all are positively correlated with PEFR. Height has the highest $r$ value of 0.7 showing most strong positive correlation. Pearson's $r$ for BMI is 0.35 showing poor but positive correlation (Table 3 ).

Table 1: Demographic details of the students

\begin{tabular}{lc}
\hline & Mean \pm SD \\
\hline Age (years) & $12.32 \pm 2$ \\
Weight (kg) & $35.7 \pm 9.7$ \\
Height (meter) & $1.46 \pm 0.12$ \\
BMI & $16.5 \pm 2.7$ \\
\hline
\end{tabular}

Table 2: Mean peak expiratory flow rate for different body mass index range

\begin{tabular}{|lc|}
\hline \multicolumn{1}{|c}{ BMI } & Mean PEFR \\
\hline Underweight $\left(<5^{\text {th }}\right.$ centile $)$ & 246 \\
\hline Normal $\left(>5^{\text {th }}\right.$ to $85^{\text {th }}$ centile $)$ & 259 \\
\hline Overweight $\left(85^{\text {th }}\right.$ to $95^{\text {th }}$ centile $)$ & 256 \\
\hline
\end{tabular}

Table 3: Correlation of anthropometric variables and age with peak expiratory flow rate

\begin{tabular}{ccccc}
\hline & Height & Weight & BMI & Age \\
Pearson's r /(P value) & $0.7 /(0.00)$ & $0.64 /(<0.01)$ & $0.35 /(0.01)$ & $0.65(<0.01)$ \\
\hline
\end{tabular}

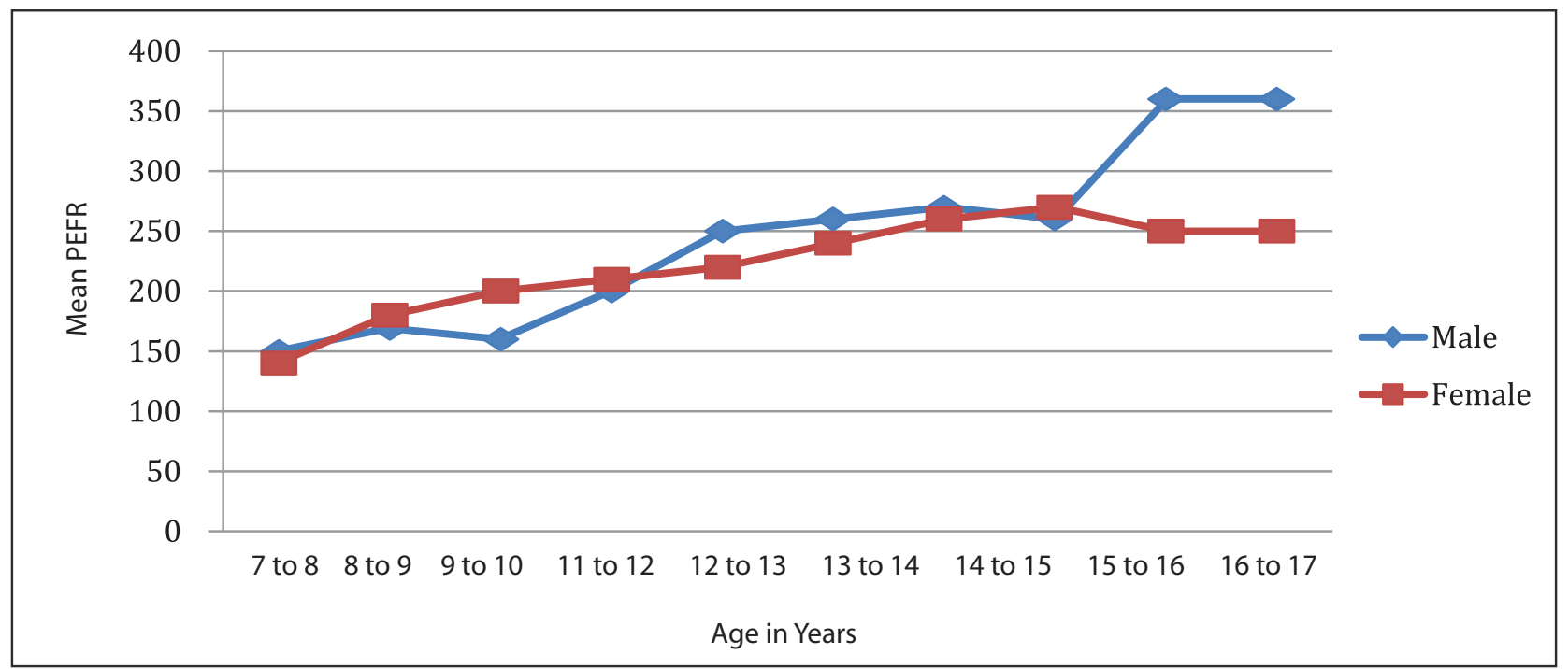

Figure 1: Change in mean peak expiratory flow rate at different age for male and female 


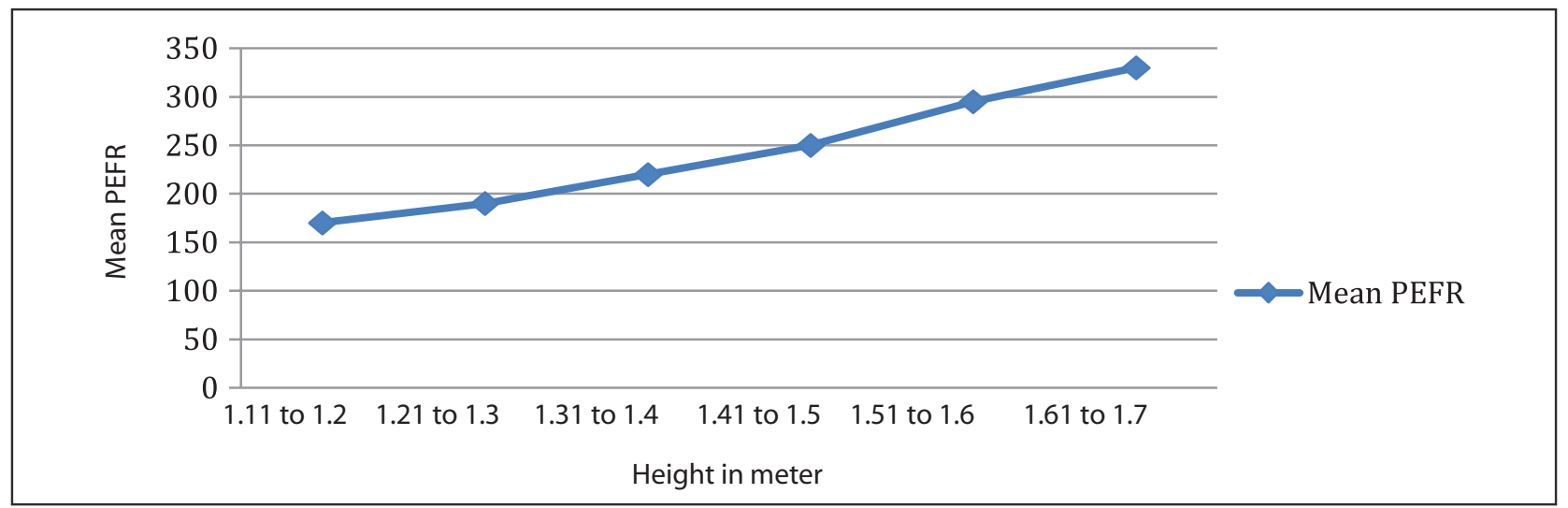

Figure 2: Change in mean peak expiratory flow rate with height

\section{DISCUSSION}

In our study PEFR increased with increase in BMI contrary to the Western studies which showed decrease in PEFR with increase in $\mathrm{BMI}^{6,7}$. Basuli Goswami et al in have documented a negative correlation between increasing obesity and BMI, along with other obesity indices ${ }^{6}$. Similarly, Zuhal Gundogdu et al and Paralikar SJ et al in a comparative study showed a significantly low PEFR in obese group compared to non-obese ${ }^{7}$. However, a study done by Amar Taksande and his group in India has shown that BMI along with other anthropometric variables had a positive linear correlation with $\mathrm{PEFR}^{8}$. Our findings were similar to that of Amar aksande, however when we segregated the children in different categories according to their BMI and plotted a graph of mean PEFR in these three groups we found that PEFR initially increased with increase in BMI form category thinness to normal BMI and PEFR value decreased with increasing BMI from normal to overweight categories. This indicates the fact that once a child moves towards being obese, PEFR and BMI will have a negative correlation. However, as our study population was not evenly distributed between the thinness (<-1SD) normal(-1 to +2SD) and overweight $(>+2 \mathrm{SD})$ category, we were unable to get a statistically significant data. Nevertheless, it did give us the clue that increase in BMI above +2 SD impairs the pulmonary function of an individual. Pearson's $r$ for correlation of BMI and PEFR is 0.35 which indicates positive but weak correlation between the two. This result is because of the fact that our data ranged from malnourished to overweight and the two state of malnutrition have different effect on PEFR.

Out of the different anthropometric variables that we measured, height of the individual had highest positive correlation with BMI with Pearson's $r$ 0.7. Value of 0.7 indicates that PEFR and height have a linear positive correlation with increasing height. Other variables like weight, BMI and age are also positively correlated but with value less than 0.7 . These results are similar to other studies that have also shown that height is one anthropometric variable which is strongly correlated with change in PEFR ${ }^{3-7,10}$. Small number of the student population is the major limitation of this study. We suggest to repeat similar study in large number with different strata of population in different nutritional status, and ethnic group.

\section{CONCLUSION}

PEFR increases with the increasing BMI till person's BMI moves from -1SD to +2SD and as BMI moves towards overweight range i.e.>2SD PEFR starts declining. Among the anthropometric variable and age, height is one such variable which has highest positive correlation with PEFR.

\section{ACKNOWLEDGEMENTS}

I would like to express my sincere gratitude to Professor Dr. Pushpa Raj Sharma who helped me in every step during thesis writing and also while writing this research article. 


\section{REFERENCES}

1. Mrindha $M$, Amin $M$, Kabir A. Peak Expiratory Flow Rate (PEFR)-A Simple Ventilatory Lung Function Test. JSSMC. Oct $2012 ; 3(2): 44-7$ [DOI]

2. Philips N, Krucik G. Peak Expiratory Flow Rate [Internet]. 2012 July 20. Available from: http:// www.healthline.com/health/peak-expiratory-flowrate\#overview[DOI]

3. Seo WH, Ahn SH, Park SH, Kim J, Ahn KM, Ko BJ et al. The standard range of peak expiratory flow rates of Korean children. Asian Pac J Allergy Immunol. 2011 Jun;29(2):143-9.[PubMed]

4. Li AM, Chan D, Wong E, Yin J, Nelson EA, Fok TF. The effects of obesity on pulmonary function. Arch Dis Child. 2003 April; 88(4):361-3 [PubMed]

5. Faridi MM, Gupta P, Prakash A. Lung functions in malnourished children aged five to eleven years. Indian Pediatr. 1995 Jan;32(1):35-42 [PubMed]
6. Goswami B, Roy AS, Dalui R. Peak Expiratory Flow Rate - A Consistent Marker of Respiratory Illness Associated with Childhood Obesity. 2014; 2(1): 2126 [DOI]

7. Gundogdu Z, Eryilmaz N. Correlation between peak flow and body mass index in obese and non-obese children in Kocaeli, Turkey. Prim Care Respir J. 2011 Dec;20(4):403-6 [PubMed]

8. Paralikar SJ, Kathrotia RG, Pathak NR. Assessment of pulmonary functions in obese adolescent boys. Lung India. 2012 Jul;29(3):236-40 [PubMed]

9. Taksande A, Jain M, Vilhekar K, Chaturvedi P. Peak expiratory flow rate of rural school children from Wardha district, Maharashtra in India. World J Pediatr 2008 Aug;4(3):211-4 [Full Text]

10. Dhungel KU, Parthasarathy D, Dipali S. Peak expiratory flow rate of Nepalese children and young adults. KUMJ. April 2009;6(23):346-54 [PubMed] 